\title{
OBTENCIÓN Y CARACTERIZACIÓN DE ABONO ORGÁNICO LÍQUIDO A TRAVÉS DEL TRATAMIENTO DE EXCRETAS DEL GANADO VACUNO DE UN ESTABLO LECHERO USANDO UN CONSORCIO MICROBIANO ÁCIDO LÁCTICO
}

\section{OBTAINING AND CHARACTERISING AN ORGANIC LIQUID FERTILIZER DUE TO THE TREATMENT OF DAIRY FARM CATTLE MANURE USING A LACTIC ACID MICROBIAL CONSORTIUM}

\author{
Liliana Peralta-Veran ${ }^{1}$, Juan Juscamaita-Morales² y Víctor Meza-Contreras ${ }^{3}$
}

\begin{abstract}
Resumen
En los sistemas de producción animal se generan grandes cantidades de excretas que ocasionan impactos ambientales negativos. No obstante, éstas son fuentes de nutrimentos para la elaboración de abonos orgánicos. La siguiente investigación tiene como objetivo proponer un sistema biológico acelerado (5 días) para la obtención de abonos orgánicos. De este modo, se pretrataron excretas frescas de ganado vacuno y se aplicaron 25 tratamientos con las excretas tratadas (ET) en una proporción hasta del 100\%, melaza de caña de azúcar y como inóculo el consorcio microbiano ácido láctico (B-lac) en la proporción de 0, 5, 10, 15 y 20 \% (v/p) respectivamente, bajo un Diseño Completo al Azar (DCA) con arreglo factorial 5x5. Se utilizó la prueba de la comparación de rangos múltiples de Tukey a un nivel de significancia de 0.05 y la de Mínimos Cuadrados para el efecto de interacción melaza y B-lac. Los tratamientos fueron evaluados por un período de 21 días y los resultados mostraron al tratamiento T20 (20\% melaza, 15 \%B-lac y 65\% ET) como el mejor tratamiento que cumplió los requerimientos planteados de pH más bajo $4.02 \mathrm{y}$ acidez más alta en el menor tiempo de $2.06 \%$ en ácido láctico; además T20 estuvo exento de agentes patógenos y presentó buenas propiedades agronómicas de nitrógeno $4200 \mathrm{mg} \mathrm{L}^{-1}$, de fósforo $744 \mathrm{mg} \mathrm{L}^{-1}$, potasio $17200 \mathrm{mg} \mathrm{L}^{-1}$, materia orgánica $181 \mathrm{~g} \mathrm{~L}^{-1} \mathrm{y}$ un alto contenido de micronutrimentos. El tratamiento biotecnológico usado permitió darle valor agregado a las excretas, transformándolas en abonos orgánicos de interés agronómico, estables y libres de agentes patógenos.
\end{abstract}

Palabras clave: biol, excretas pretratadas, consorcio microbiano, ácido láctico.

\begin{abstract}
Animal production systems generate large amounts of excreta that cause negative environmental impacts. However, these are a source of nutrients for the production of organic fertilizers. The following research had the objective of proposing a rapid biological system (5 days) devised to obtain an agronomic organic fertilizer. Thus, 25 treatments (ET) were applied to initially pretreated fresh cattle manure in proportions up to $100 \%$ of molasses of sugar cane and lactic acid inoculum (B-lac) in ratios of 0, 5, 10, 15 and 20\% (v/ w) respectively. A Random Complete Design with factorial arrangement $5 \times 5$ was used and mean differences were established with Tukey and Least Square Means for the effect of molasses and B-lac. Treatments were evaluated for a period of 21 days and the results showed that T20 treatment (20\% molasses, $15 \%$ B-lac and $65 \%$-lac ET) resulted in the best treatment which fulfilled elevated requirements of lower $\mathrm{pH} 4.02$, higher acidity in shortest time of $2.06 \%$ lactic acid. T20 was free of pathogens and had good agronomic properties of $4200 \mathrm{mg} \mathrm{L}^{-1}$ of nitrogen, $744 \mathrm{mg} \mathrm{L}^{-1}$ of phosphorus and 17200 mg $\mathrm{L}^{-1}$ of potassium, $181 \mathrm{~g} \mathrm{~L}^{-1}$ of organic material and a high content of micronutrients. The biotechnological treatment used enabled to provide a higher value to the excreta, transforming them into a stable, pathogen free agronomic organic fertilizer.
\end{abstract}

Key words: biol, manure treated, microbial consortium, lactic acid. 


\section{Introducción}

En un sistema de producción animal, el nitrógeno no metabolizado por los animales en la producción de proteínas como leche, carne o huevos es excretado en la orina y las heces, luego dicho nitrógeno es liberado hacia el medio ambiente en forma de amonio durante la descomposición del estiércol a través de la acción de la microflora presente (Gay \& Knowlton, 2009), de esa forma se pierden nutrimentos que podrían ser aprovechados para la elaboración de abonos orgánicos. Por tal motivo, se recomienda que en los sistemas de producción se vigile el balance de nutrimentos suministrado para minimizar los riesgos ambientales y el ahorro en costos de producción (Koelsch \& Lesoing, 1999).

Según Rivas et al. (2008), los desechos del ganado lechero como el estiércol y purinas generan problemas de salud en la población por la contaminación de aguas subterráneas causada por nitratos, la contaminación del aire por amonio, metano, malos olores y la transmisión de enfermedades por insectos vectores. Además, dichos desechos causan la degradación de los ecosistemas acuáticos por la contaminación de aguas superficiales (eutrofización), también generan la pérdida de fertilidad del suelo (salinización) y son causantes de la problemática del calentamiento global. Esto dado que, entre los mamíferos herbívoros más importantes dentro de la economía de la alimentación humana, se encuentran los rumiantes, y entre estos están las vacas, ovejas y cabras, animales domésticos que cuentan con un órgano especial denominado rumen, en cuyo interior se lleva a cabo la digestión de la celulosa y otros polisacáridos vegetales mediante la actividad de poblaciones microbianas. En el rumen se acumula gran cantidad de metano $\left(\mathrm{CH}_{4}\right)$ y anhídrido carbónico $\left(\mathrm{CO}_{2}\right)$, siendo la composición media de un $65 \%$ de $\mathrm{CO}_{2}$ y de $35 \%$ de $\mathrm{CH}_{4}$ y es en los eructos del rumiante donde se expulsan estos gases al exterior (Madigan et al., 2004). Asimismo, Gay \& Knowtlon (2009), mencionan que la legislación americana ha puesto particular atención a las emisiones de amonio generados en la actividad pecuaria debido al incremento de las emisiones atmosféricas del amonio reportados por la Agencia de Protección Ambiental (EPA) en los Estados Unidos.

Por otra parte, la cantidad de estiércol que puede producir un animal por año, así como la cantidad relativa de sustancias que pasa a formar parte del estiércol varía de acuerdo a la alimentación, el tipo de cama (arena, aserrín, paja) y la especie. Se estima que el estiércol total producido por una vaca lechera de $600 \mathrm{~kg}$ de peso es de $18300 \mathrm{~kg}$ año-1 y el de un vacuno de carne de $350 \mathrm{~kg}$ de peso es de 10950 kg/año (Guerrero, 1993). Asimismo, los animales excretan al ambiente entre 60 y $80 \%$ del nitrógeno $(\mathrm{N})$ y el fósforo $(\mathrm{P})$ que ingieren, a través de la orina y las heces (Van Horn et al, 1994). Kolesch \& Lesoing
(1999) refieren por ello que la mayoría de los nutrimentos suministrados a los animales no se comercializan como carne y otros productos, sin embargo se mantienen en los sistemas de producción animal como estiércol.

En la actualidad, son diversos los usos y tratamientos que se dan a las excretas, entre ellos se tiene la técnica del compostaje, por la cual el estiércol es madurado, favoreciendo la formación de un material prehumificado fácilmente mineralizable y con importante carga bacteriana beneficiosa, el proceso dura 3 a 6 meses a veces más tiempo dependiendo del manejo y de las características del material de partida (Labrador, 2001). El estiércol vacuno puede ser utilizado en la producción de biogás como fuente alternativa de energía renovable, mediante la técnica de biodigestión, proceso anaeróbico y de alimentación continua mediante el uso de los biodigestores. Como producto residual de la biodigestión se obtiene un efluente líquido (biol) y sólido (biosol) que pueden ser usados como abonos orgánicos también denominados bioabonos. Asimismo, por medio de esta técnica se obtiene beneficios funcionales por la reducción de los gases causantes del efecto invernadero (Aguilar \& Botero, 2006). Según Herrero \& Gil (2008), el tratamiento de las excretas, en general, consiste en disminuir la carga orgánica que contienen y dichos sistemas de tratamiento varían bastante entre tipos de producción, regiones y países, siendo el tratamiento más frecuente el de efluentes provenientes de la limpieza de las instalaciones a través de las lagunas de lixiviación.

Según Martínez et al. (2008), algunos investigadores han recurrido al proceso de ensilaje para aprovechar el máximo contenido de nutrimentos de las excretas, por este método, se logra el control de patógenos, se mejora la calidad tanto nutritiva como la aceptación del producto por los animales. Además, mediante la fermentación anaerobia, la materia orgánica produce un residuo orgánico de excelentes propiedades agronómica, siendo la composición del bioabono en promedio de $8.5 \%$ de materia orgánica, $2.6 \%$ de nitrógeno, $1.5 \%$ de fósforo, $1.0 \%$ de potasio a un pH de 7.5 (Botero \& Preston, 1987).

La elaboración del biol se realiza en forma artesanal, dependiendo su composición y propiedades del contenido nutricional de los materiales con los que se ha elaborado. Asimismo, la obtención del biol depende del clima y de las características del biodigestor en el sistema de digestión anaeróbico; en el Perú a través del Instituto de Investigación Agraria (INIA, 2008), existen dos formas de preparar el biol, en mangas de plástico (modelo de flujo pistón) o bidones (simulando el modelo chino o hindú), donde los insumos del biol permanecen por un período de 2 a 3 meses, tiempo promedio que dura la fermentación. En clima frio dura entre 75 a 90 días, mientras que en un clima cálido dura entre 30 a 45 días. Asimismo, 
estudios realizados en la elaboración del biol han determinado que existen riesgos de contaminación para las personas que lo preparan como para los agricultores que lo aplican. Sotil (2007), menciona que existen altos niveles de coliformes totales $\mathrm{y}$ fecales al inicio de la biodegradación de los abonos $\left(10^{7}-10^{8} \mathrm{NMP} / 100 \mathrm{~mL}\right)$, que se llegan a reducir a $10^{3}$ NMP/100 mL luego de 61 días; y llegándose a niveles cercanos a cero a los 335 días de iniciado el experimento.

Los consorcios microbianos B-lac, son bacterias ácido lácticas, consiste en un cultivo líquido que contiene bacterias probióticas del género Lactobacillus, Streptococcus y Bifidobacterium (García, 2008). El uso del Consorcio Microbiano B-lac ha permitido la obtención de bioabonos a través de procesos de fermentación anaeróbica se han podido degradar diversas materias orgánicas como hidrolizado de pescado, macroalgas, residuos de pota y residuos de pescado (Bossio, 2007; Aldon, 2008; Peña, 2008 y García, 2008), en dichos estudios se evaluaron el comportamiento microbiano, y se monitoreó como el parámetro importante el $\mathrm{pH}$ cuyo descenso durante el proceso permitió garantizar la obtención de un fertilizante orgánico libre de patógenos; de igual manera se analizaron los parámetros fisicoquímicos y la composición química de dichos abonos orgánicos líquidos. Asimismo, dichos abonos orgánicos fueron usados en pruebas de germinación estándar, determinando el potencial máximo de germinación en un lote de semillas de maíz y en pruebas en invernadero utilizando las primeras etapas del crecimiento en maíz.

El presente trabajo de investigación tiene como objetivo proponer una nueva técnica en la elaboración de un biol más rápido en cuanto al tiempo de obtención del bioabono, usando el Consorcio Microbiano B-lac, y las excretas frescas del ganado vacuno provenientes del establo lechero de la Unidad Experimental de Zootecnia (UEZ) de la Universidad Nacional Agraria La Molina (UNALM). Además, se propone la gestión de residuos orgánicos sólidos generados en el establo, dándole un valor agregado y generando oportunidades de beneficios económicos y ambientales mediante dicha innovación tecnológica.

\section{Materiales y métodos.}

Residuos orgánicos: Excretas frescas de ganado vacuno lechero de la raza Holstein, proveniente del establo lechero de la Unidad Experimental de Zootecnia - UNALM.

Microorganismos: Consorcio de bacterias ácido lácticas de los género Lactobacillus, Streptococcus, Bifidobacteriun (B-lac) (García, 2008)

T: Tratamiento elaborado en el Laboratorio de Biotecnología Ambiental y Biorremediación de la Facultad de Ciencias - UNALM.

Melaza de caña: Fuente de carbohidrato soluble, macronutrimentos, micronutrimentos y factores de crecimiento, obtenidos del establo de la Universidad Nacional Agraria La Molina (UNALM).

Condiciones iniciales: La toma de muestra de excretas del establo se realizó en base a la colecta de excretas de distintas vacas para obtener una muestra representativa, siendo luego transportadas al laboratorio para su pre-tratamiento. Posteriormente, se tomaron cinco muestras representativas de las excretas para realizar el análisis del porcentaje de humedad a través del método de evaporación hasta peso constante por medio del secado a $70{ }^{\circ} \mathrm{C}$ durante $48 \mathrm{~h}$, temperatura recomendada para alimentos vegetales, a fin de reducir al mínimo la destrucción de carbohidratos (AOAC, 1998).

Pre-tratamiento: Después de la recolección de las excretas frescas, las muestras fueron calentadas a 80 ${ }^{\circ} \mathrm{C}$ durante $15 \mathrm{~min}$, siendo homogeneizadas por agitación, este procedimiento se realizó con el objetivo de disminuir la carga microbiana presente en las excretas. Posteriormente la muestra fue enfriada hasta $40^{\circ} \mathrm{C}$ para su inoculación.

Tratamiento de las excretas pre-tratadas (EP): Se obtuvo un peso final de $1.5 \mathrm{~kg}$ por cada uno de los 25 diferentes tratamientos (Tabla 1), se adicionaron el porcentaje de melaza y el Consorcio Microbiano B-lac siendo luego mezclados y homogenizados en bolsas de polietileno. Por cada tratamiento se consideraron tres repeticiones de 500 g cada una. Luego, se propició un ambiente anaeróbico sellándolos herméticamente.

Los tratamientos fueron transferidos a una cámara de incubación a $40{ }^{\circ} \mathrm{C}$ durante 21 días, evaluándose directamente los parámetros de $\mathrm{pH}$ y conductividad eléctrica, indicadores del proceso de fermentación. Se procedió a la selección de los tratamientos que cumplieran los siguientes criterios, para ser considerado como buen tratamiento: $\mathrm{pH} \leq 4.5$, que el

Tabla 1: Composición de los 25 tratamientos en base a melaza, consorcio microbiano y excreta pre-tratada al $100 \%$ en peso.

\begin{tabular}{cccccccc}
\hline T & $\begin{array}{c}\text { Melaza } \\
(\%)\end{array}$ & $\begin{array}{c}\text { B-lac } \\
(\%)\end{array}$ & $\begin{array}{c}\text { EP } \\
(\%)\end{array}$ & T & $\begin{array}{c}\text { Melaza } \\
(\%)\end{array}$ & $\begin{array}{c}\text { B-lac } \\
(\%)\end{array}$ & $\begin{array}{c}\text { EP } \\
(\%)\end{array}$ \\
\hline T1 & 0 & 0 & 0 & T14 & 15 & 10 & 75 \\
T2 & 5 & 0 & 95 & T15 & 20 & 10 & 70 \\
T3 & 10 & 0 & 90 & T16 & 0 & 15 & 85 \\
T4 & 15 & 0 & 85 & T17 & 5 & 15 & 80 \\
T5 & 20 & 0 & 80 & T18 & 10 & 15 & 75 \\
T6 & 0 & 5 & 95 & T19 & 15 & 15 & 70 \\
T7 & 5 & 5 & 90 & T20 & 20 & 15 & 65 \\
T8 & 10 & 5 & 85 & T21 & 0 & 20 & 80 \\
T9 & 15 & 5 & 80 & T22 & 5 & 20 & 75 \\
T10 & 20 & 5 & 75 & T23 & 10 & 20 & 70 \\
T11 & 0 & 10 & 90 & T24 & 15 & 20 & 65 \\
T12 & 5 & 10 & 85 & T25 & 20 & 20 & 60 \\
T13 & 10 & 10 & 80 & & & & \\
\hline
\end{tabular}


$\mathrm{pH}$ disminuya rápidamente a valores cercanos o menores de 4.0, ausencia del mal olor, sin formación de capas de mohos o levaduras. Luego se comprobará mediante la prueba estadística el grado de significación de la interacción de los factores Melaza y B-lac sobre el parámetro de $\mathrm{pH}$.

Luego de la selección en base a los criterios ya descritos se repitió la prueba, se utilizaron $2 \mathrm{~kg}$ de peso como peso total de EP, Melaza y B-lac, obteniéndose 4 muestras por tratamiento, la cuarta muestra fue empleada para las evaluaciones de CE y porcentaje de acidez titulable y pH. En esta segunda selección de los tratamientos se realizó la prueba de Mínimos Cuadrados de las Medias.

Estabilidad de los tratamientos: Se evaluaron la evolución del $\mathrm{pH}$, la $\mathrm{CE}$ y el porcentaje de acidez titulable durante 30 días, después de finalizado el proceso de fermentación.

Métodos de Análisis

Medición de pH: La medición del pH fue a través del método potenciométrico, medición directa, introduciendo el electrodo del potenciómetro en la muestra. Se consideró como lectura válida al valor que se mantuvo por $10 \mathrm{~s}$ constante. El equipo previamente fue calibrado usando las soluciones tampón de $\mathrm{pH} 4$ y 7.

Conductividad eléctrica: Mediante el método de conductimetría, se determinó por medición directa, introduciendo el electrodo del conductímetro en la parte líquida de las muestras obtenidas, previamente centrifugados a $5000 \mathrm{rpm}$ durante $30 \mathrm{~min}$; previa calibración del conductímetro con el tampón de solución salina patrón de 1433 uS cm-1.

Medición del porcentaje de acidez titulable: Se determinó mediante la medición indirecta del ácido láctico titulable según la metodología de la AOAC (1998).

Análisis microbiológico: $\quad$ El análisis microbiológico (numeración de coliformes totales, numeración de coliformes fecales, numeración de Staphylococcus aureus y el conteo de mohos y levaduras) de la excreta fresca y de los tratamientos seleccionados se realizó siguiendo la metodología de la International Commission on Microbiological for Food (ICMSF, 1983).

Análisis fisicoquímicos: Para el análisis de los tratamientos seleccionados se evaluaron el $\mathrm{pH}$, conductividad eléctrica, sólidos totales, materia orgánica en solución; concentración de Nitrógeno total, Fósforo total, Potasio total, Calcio, Magnesio, Sodio, Fierro, Cobre, Zinc, Manganeso y Boro (Capman \& Pratt, 1973).

Cálculo de relación $\mathrm{C} / \mathrm{N}$ : Se realizó el cálculo de proporción de las materias de mezcla en base al manejo agrícola de abonos en cuanto a la estabilidad del producto obtenido mediante la relación $\mathrm{C} / \mathrm{N}$.
$\mathrm{C} / \mathrm{N}=\frac{\% \mathrm{C} \text { estiércol } \mathrm{x} \% \text { estiércol }+\% \mathrm{C} \text { melaza } \mathrm{x} \% \text { melaza }}{\% \mathrm{~N} \text { estiércol } \mathrm{x} \% \text { estiércol }+\% \mathrm{~N} \text { melaza } \mathrm{x} \% \text { melaza }}$

Análisis de datos

El análisis estadístico de los datos se realizó mediante un Análisis de Varianza, el diseño experimental fue completamente al azar (DCA) con arreglo factorial $5 \times 5$ y tres repeticiones. Para determinar si existía diferencia estadísticamente significativa entre las dosis de B-lac y Melaza se realizó la prueba de comparación de medias de rangos múltiples de Tukey a un nivel de significancia de 95\% ( $\mathrm{p}<0.05)$. Se utilizó el software SAS versión 8.2 (SAS Institute Inc., Cary, NC).

\section{Resultados y discusión.}

Condiciones iniciales de las excretas frescas: El $\mathrm{pH}$ promedio se encontró cercano a la neutralidad (6.98) y resultó ser menor al valor reportado por Guerrero (1993) que fue de 8.3. No obstante, el pH de las excretas puede variar entre 6 y 8 dependiendo de la alimentación, de la raza, clasificación del vacuno de o a la frescura de las excretas. El porcentaje promedio de humedad de las excretas frescas fue del $80.0 \pm 0.9$ \% valor cercano al reportado por Van Horn et al. (1994) de 78.7\% para las excretas de vacas lecheras de la raza Holstein de $635 \mathrm{~kg}$ de peso.

El pH alcalino de las excretas se debe principalmente a la acción microbiana sobre las proteínas que se encuentran en los nutrimentos no asimilados por los animales en el sistema de producción animal intensiva, promoviéndose la generación de amoníaco, este a su vez al encontrarse en un ambiente de humedad reacciona con el agua provocando la alcalinización de las excretas. Asimismo, la proporción de Nitrógeno en la dieta, afecta la producción de amoníaco, así como una proporción elevada de almidón que aumenta la posibilidad de que no se digiera y que aparezca en la materia fecal, luego este fermente en el ambiente y produzca olores intensos (Miller et al., 2006).

Excretas pre-tratadas (EP): La humedad según las condiciones del pre-tratamiento estuvieron cercanos al $60 \%$, perdiéndose un $20 \%$ por el tratamiento térmico. No obstante, mantuvieron una consistencia pastosa, permitiendo una fácil manipulación.

Evaluación del pH y primera selección de los tratamientos: Se determinó el rango de pH 5.10-6.97, para los 25 tratamientos al inicio de la fermentación. Los tratamientos T1, T6, T11, T16 y T21 que tuvieron en su composición solo EP y el cultivo microbiano Blac, mostraron $\mathrm{pH}$ mayores al de los iniciales, presentaron características de olores desagradables a putrefacto, con presencia de burbujas en la superficie de las muestras al tercer y quinto de día de incubación, esto se debió a la ausencia de fuente carbonada de fácil asimilación, no permitió la proliferación de las bacterias lácticas del consorcio microbiano. Las 


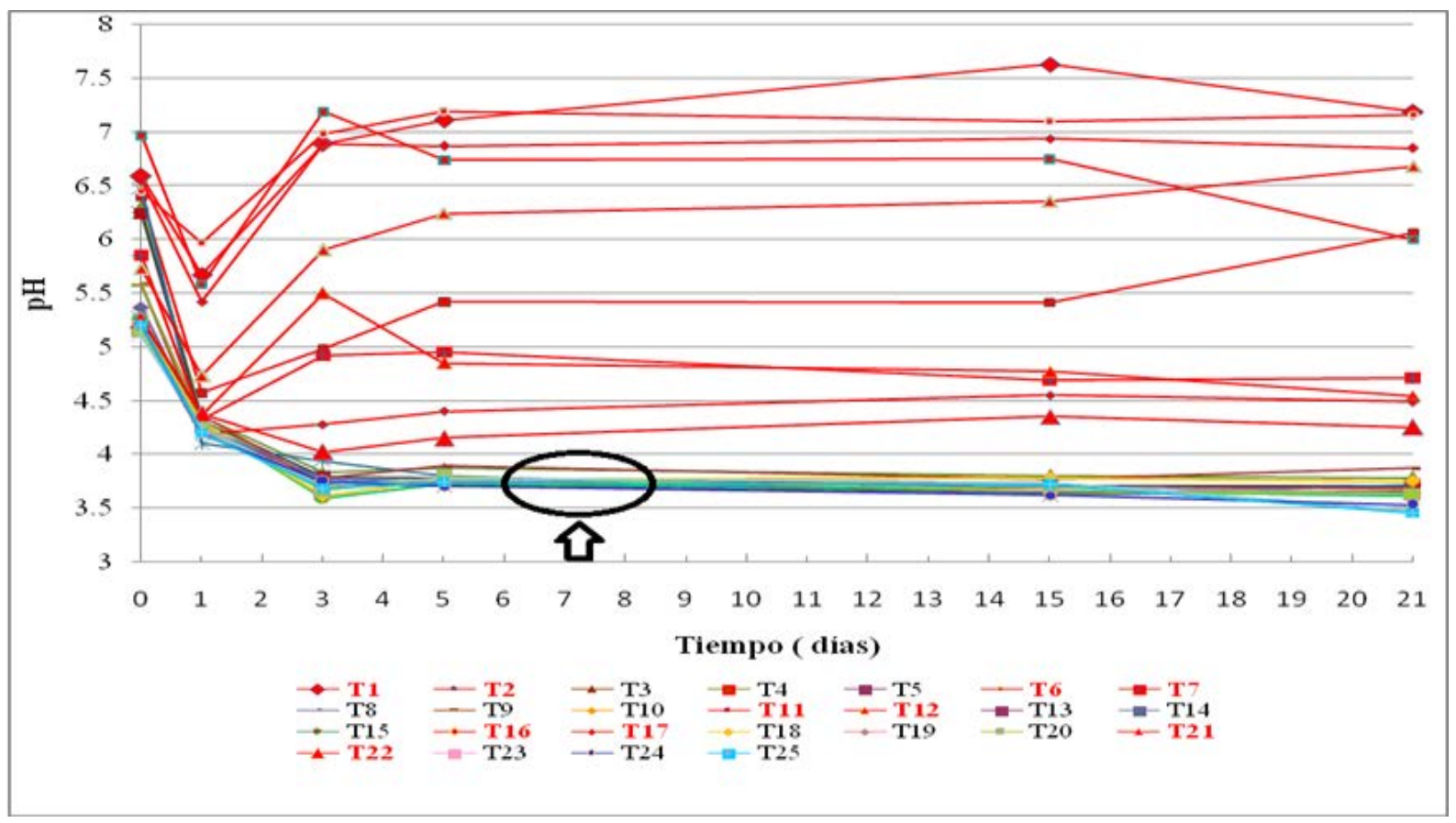

Figura 1. Variación del pH en los tratamientos en función del tiempo (la flecha indica los tratamientos seleccionados).

condiciones de $\mathrm{pH}$ mayor a 5 y temperatura de incubación de $40{ }^{\circ} \mathrm{C}$ favorecen el desarrollo de la flora bacteriana autóctona (García, 2008).

Los tratamientos T2, T7 y $\mathrm{T} 12$ resultaron con $\mathrm{pH}$ mayores de 4.5, al tercer día presentaron burbujas en la cubierta del plástico como espacios en el interior de las muestras como resultado de los gases generados, indicador de microorganismos productores de $\mathrm{CO}_{2}$ al parecer por la presencia de melaza $(5 \% \mathrm{p} / \mathrm{v})$ como fuente de Carbono, no siendo la concentración suficiente para permitir el dominio de las bacterias benéficas del inóculo B-lac en cuanto a la proliferación de los microorganismos homolácticos. Los tratamientos T17 y T22 al 5\% de melaza presentaron coloraciones verdosas y blanquecinas en la superficie en contacto con la cubierta de plástico.

Se determinó que los tratamientos sin melaza y los que contenían 5\% de melaza no alcanzaron los requerimientos necesarios para su selección, por lo que fueron descartados dichos tratamientos se muestran en las curvas de color rojo de la Figura 1, además, en la Figura se muestran los 15 tratamientos seleccionados, los cuales se encuentran encerrados y señalados por la flecha, estos mostraron un descenso rápido de $\mathrm{pH}$ al tercer día de fermentación, luego de un ligero aumento al quinto día, y posteriormente los valores fluctuaron entre 3.5 y 4 manteniéndose hasta el día 21 de evaluación. Boucourt et al., (2006) mencionan la fermentación de la caña con excreta vacuna disminuye los niveles de $E$. coli a las $48 \mathrm{~h}$ y que en el producto fresco predominan aerobios totales, lactobacilos y levaduras, mientras que en el producto seco, el grupo predominante fueron los aerobios totales. En los tratamientos evaluados, la fermentación sobre los sustratos tanto de excreta pretratada y melaza como el pre tratamiento de las excretas permitieron que los microorganismos competentes se vieran afectados por las condiciones de acidez logrados en los tratamientos favoreciendo el crecimiento de las bacterias del B-lac.

Segunda selección de los tratamientos: Se repitió el experimento bajo las condiciones iniciales, el $\mathrm{pH}$ de la excreta fresca fue de 7.13. Los valores iniciales de $\mathrm{pH}$ de los tratamientos al tercer día resultaron mayores a los registrados en el ensayo de selección previo, esto pueda ser debido al $\mathrm{pH}$ de la muestra excreta inicial, en la primera selección fue de $\mathrm{pH} 6.98$ dando valores de $\mathrm{pH}$ entre 3.72 a 3.89 al tercer día para 15 de los tratamientos (Figura 1); mientras que en la segunda selección la muestra de excreta inicial presentó un $\mathrm{pH}$ 7.13 obteniéndose valores entre $\mathrm{pH} 4.03$ para T20 y pH 4.38 para T18.

En la Figura 2, se muestra el efecto de interacción que ejercen el consorcio microbiano B-lac (B) con la fuente carbonada melaza (M) sobre el parámetro de $\mathrm{pH}$ al quinto día de evaluación de los tratamientos seleccionados. Los tratamientos que mostraron menores valores de $\mathrm{pH}$ al quinto día fueron T20 (15\% B-lac, $20 \%$ melaza) y T23 (20 \% B-lac, 10\% melaza) pH 4.02 y 4.03 respectivamente. Según el análisis estadístico existe diferencia estadísticamente significativa $(\mathrm{p}<0.0001)$ para la interacción Melaza y B-lac.

El efecto de interacción entre melaza y B-lac sobre el $\mathrm{pH}$ es significativo ( $\mathrm{p}<0.05$ ), los mejores tratamientos fueron T20, T23 y T8 que desarrollaron 


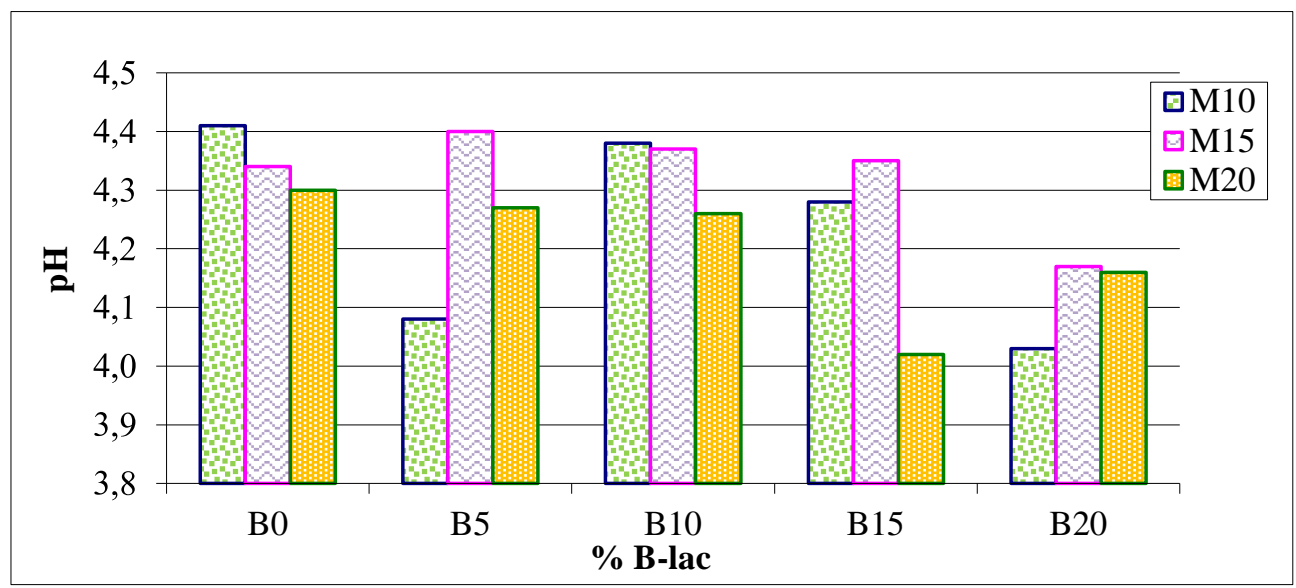

Figura 2. Efecto de interacción de B-lac y melaza sobre el parámetro de pH en los quince tratamientos seleccionados.

valores de pH más bajos en comparación a los demás tratamientos. Así, mediante la prueba de Mínimos Cuadrados para las medias de $\mathrm{pH}$ de los tratamientos se muestran en la Tabla 2, con valores de $\mathrm{pH} 4$, condiciones ácidas por las cuales los Lactobacillus son resistentes a diferencia de otras bacterias (Madigan, 2004).

Análisis del parámetro de CE: Se determinó un aumento en el contenido de sales, de 14.80 a $20.30 \mathrm{dS}$ $\mathrm{m}^{-1}$ para el tratamiento T3 (M10-B0) en ausencia del consorcio microbiano, en comparación con el tratamiento T20 (M20-B15) de 24.50 a $26.40 \mathrm{dS} \mathrm{m}^{-1}$, siendo la variación menor para el T20 en comparación con los demás tratamientos seleccionados.

Análisis del parámetro porcentaje de acidez titulable: Los tratamientos mostraron un aumento de la acidez en todos los tratamientos hasta el día tres, los

Tabla 2. Comparación de Mínimos Cuadrados para las medias en el día 5 para el parámetro $\mathrm{pH}$ en los tratamientos seleccionados.

\begin{tabular}{ccc}
\hline Tratamientos & \%Melaza-\%B-lac & $\begin{array}{c}\text { Media y } \\
\text { agrupamiento }^{(1)}\end{array}$ \\
\hline T3 & M10-B0 & $4.407^{\mathbf{a}}$ \\
T9 & M15-B5 & $4.403^{\mathbf{a}}$ \\
T13 & M10-B10 & $4.383^{\mathbf{a}}$ \\
T14 & M15-B10 & $4.370^{\text {ab }}$ \\
T19 & M15-B15 & $4.353^{\text {ab }}$ \\
T4 & M15-B0 & $4.340^{\mathbf{b}}$ \\
T18 & M10-B15 & $4.283^{\text {bc }}$ \\
T15 & M20-B10 & $4.263^{\text {cd }}$ \\
T5 & M20-B0 & $4.220^{\text {def }}$ \\
T24 & M15-B20 & $4.167^{\text {efg }}$ \\
T25 & M20-B20 & $4.160^{\text {fg }}$ \\
T10 & M20-B5 & $4.133^{\text {gh }}$ \\
T8 & M10-B5 & $4.077^{\text {hij }}$ \\
T23 & M10-B20 & $4.033^{\text {ij }}$ \\
T20 & M20-B15 & $4.020^{\mathbf{j}}$ \\
\hline
\end{tabular}

Valores sin letras en común son significativamente diferente $(\mathrm{p}<0.05)$. cuales tienden a estabilizarse hasta el quinto día. Según, García (2008), el ácido láctico titulable, genera los cambios de $\mathrm{pH}$ hacia la acidez originando condiciones de antagonismo que no permiten el desarrollo de las bacterias putrefactivas y patógenas. Asimismo, con este parámetro se indica la cantidad de ácido producido por las bacterias lácticas durante el proceso de fermentación.

Relación de los parámetros $\mathrm{pH}$ y porcentaje de ácido láctico titulable: En la Figura 3 se muestra la relación inversa que existe entre dichos parámetros. Según Garcés et al. (2004) en una fermentación láctica espontánea en condiciones anaerobias, las bacterias ácido lácticas fermentan los carbohidratos hidrosolubles, produciendo ácido láctico y en menor cantidad ácido acético, al generarse dichos ácidos el pH del material fermentado baja a un nivel que inhibe la presencia de microorganismos que inducen la putrefacción.

El tratamiento T19 (15\% Melaza, 15\% B-lac) muestra mayor contenido de ácido láctico, sin embargo no presenta el menor $\mathrm{pH}$ comparado con los demás tratamientos esto pueda deberse a la presencia de otros ácidos orgánicos. Martínez et al. (2008) indican que el patrón de fermentación observado en el estiércol a un $\mathrm{pH}$ de 4.20 muestra la presencia de ácidos grasos propiónico, butírico, acético y en una mayor proporción el ácido láctico. Los resultados muestran que para algunos tratamientos no hay una relación directa en cuanto a mayor contenido de ácido láctico titulable menor $\mathrm{pH}$ en los tratamientos como T3, T4, T5, T9, T10, T14, T15 y T19, mientras el caso contrario ocurre con el grupo de tratamientos T8, T20 y T23 que mostraron que a mayor contenido de ácido láctico titulable menor valor de $\mathrm{pH}$ (Figura 3), seguidos por el grupo T10, T24 y T25, el siguiente grupo de tratamiento con menores valores de $\mathrm{pH}$ mostrados en la Tabla 2.

En cuanto al grupo compuesto por T8, T20 y T23 que presentaron $\mathrm{pH}$ menor se seleccionó T20 debido a que muestra el pH más bajo en comparación de los 


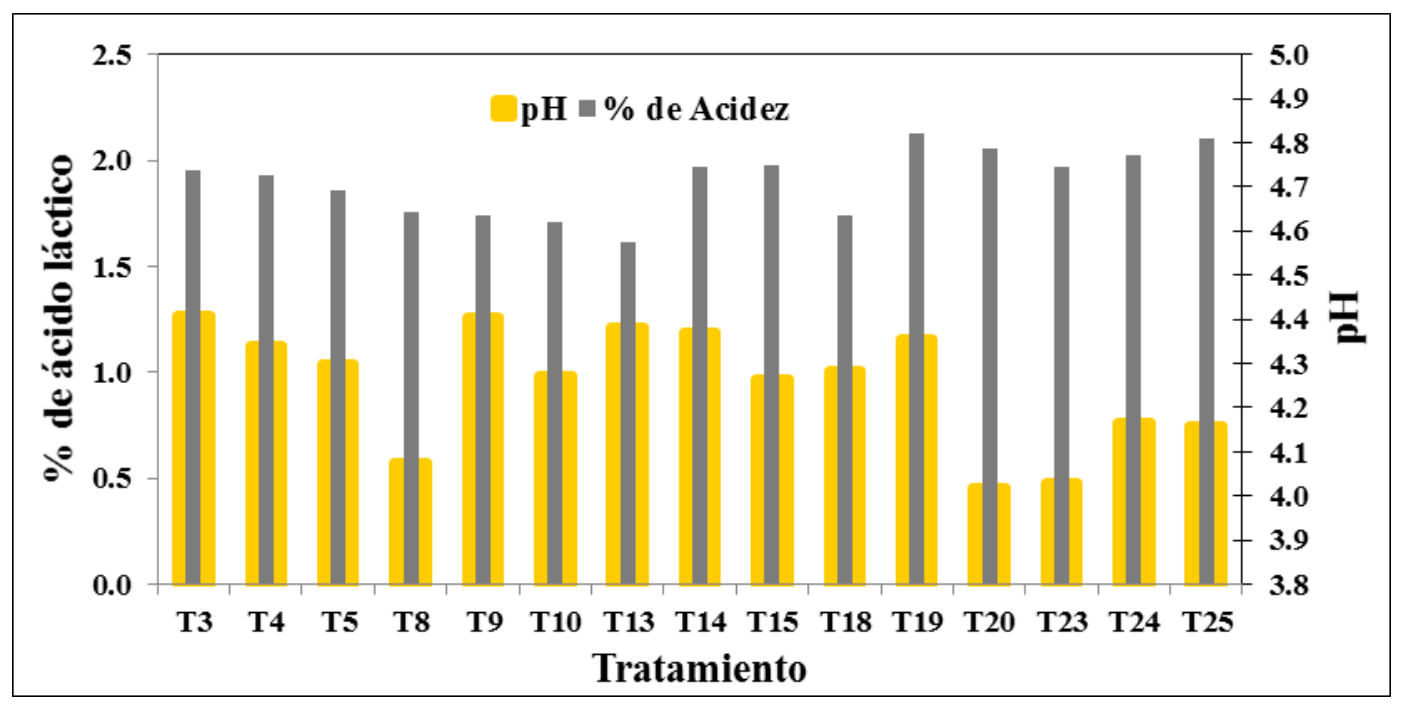

Figura 3. Porcentaje de ácido láctico titulable y pH en la evaluación al quinto día de los quince tratamientos seleccionados.

demás como se muestra en la Tabla 2 al T20 se le nombró Fastbiol 20.

Análisis microbiológico: Los resultados obtenidos en el abono líquido Fastbiol 20, dieron valores de $<3$ NMP $\mathrm{ml}^{-1}$ en coliformes totales y fecales, en un tiempo de 5 días de fermentación anaeróbica (Tabla 3), dichos resultados verifican la ausencia de microorganismos patógenos, además, muestran la disminución de la carga microbiana inicial no deseada dado por el pre tratamiento, calentamiento de las excretas ( $80^{\circ} \mathrm{C}$ durante $15 \mathrm{~min}$ ), condiciones por las cuales disminuye el número de microorganismos. Prescott et al. (2004) indican que las altas temperaturas ocasionan daños a los microorganismos al desnaturalizar las enzimas, las proteínas transportadoras y otras proteínas, asimismo, el calor también deteriora las membranas microbianas que pueden alterarse hasta el punto de inhibir su crecimientos porque el daño no puede repararse.

Los resultados obtenidos del Fastbiol 20 indican la ausencia de microorganismos patógenos en el abono orgánico líquido. Así, en cuanto al tiempo de obtención del Fastbiol 20 comparado con biol producido por digestión artesanal reportado por Sotil (2007), la reducción de los niveles de coliformes totales y fecales al y del Fastbiol 20. inicio de la biodegradación de los abonos de $10^{7}-10^{8}$ NMP $100 \mathrm{~mL}^{-1}$ llegaron a ser a los 61 días a $10^{3} \mathrm{NMP}$ $100 \mathrm{ml}^{-1} \mathrm{y}<3$ a los 335 días. De igual manera, Sotil (2007), refiere que la mayor reducción de coliformes totales y fecales se dio en los primeros 24 días, período en el cual el $\mathrm{pH}$ se redujo considerablemente, de $\mathrm{pH} 7$ y 8 llegando a pH 5 y 6 que después del día 50 se equilibró entre 7 y 8. En cuanto al Fastbiol 20 el pH logrado según el proceso de fermentación láctica generado por el Consorcio ácido láctico B-lac fue de 4.02 (Tabla 2) al quinto día. Asimismo, el ácido láctico producido y la reducción del $\mathrm{pH}$ resultan ser considerados como principal mecanismo de antagonismo microbiano de las bacterias lácticas, así Vázquez et al. (2009) refieren que la utilización de carbohidratos disponibles en el alimento, las carnes, y la reducción del $\mathrm{pH}$ a causa de los ácidos orgánicos producidos, son el principal mecanismo de antagonismo microbiano de las bacterias lácticas.

Tabla 3. Análisis microbiológico de las excretas frescas del establo lechero

\begin{tabular}{|c|c|c|}
\hline Análisis microbiológico & $\begin{array}{l}\text { Sustrato } \\
\text { inicial }{ }^{(1)}\end{array}$ & Fastbiol $20^{(2)}$ \\
\hline Enumeración de coliformes totales (NMP g ${ }^{-1}$ ) & $11 \times 10^{7}$ & ND \\
\hline Enumeración de coliformes fecales (NMP g ${ }^{-1}$ ) & $11 \times 10^{7}$ & ND \\
\hline Enumeración de coliformes totales (NMP mL ${ }^{-1}$ ) & ND & $<3$ \\
\hline Enumeración de coliformes fecales (NMP $\mathrm{mL}^{-1}$ ) & ND & $<3$ \\
\hline Numeración de mohos y levaduras (UFC mL ${ }^{-1}$ ) & ND & $<10$ estimado \\
\hline Recuento de mohos (UFC g ${ }^{-1}$ ) & $27 \times 10^{5}$ & ND \\
\hline Recuento de levaduras (UFC g-1) & $4 \times 10^{5}$ & ND \\
\hline Numeración de Staphylococcus aureus (NMP mL-1) & ND & $<3$ \\
\hline Recuento de Staphylococcus aureus (UFC g ${ }^{-1}$ ) & $34 \times 10^{6}$ & ND \\
\hline Detección de Salmonella sp. en 25 g & Ausencia & ND \\
\hline Recuento de aerobios mesófilos viables (UFC g ${ }^{-1}$ ) & $81 \times 10^{6}$ & ND \\
\hline
\end{tabular}

Nota: Valores de $<3$ y de $<10$ indican ausencia del microorganismo y ND: no determinado Fuente: (1) Análisis de excretas frescas realizado por el Laboratorio de Ecología Microbiana Marino Tabusso. (2) Análisis realizado por La Molina Calidad Total Laboratorios. 
Tabla 4. Análisis fisicoquímico del Fastbiol 20 y otros bioles.

\begin{tabular}{|c|c|c|c|c|c|}
\hline Ensayos & B V & (2) & $\begin{array}{l}\text { Biol con } \\
\text { alfalfa } \\
\text { (3) }\end{array}$ & $\begin{array}{c}\text { Biol } \\
\text { con } \\
\text { chicha } \\
\text { jora } \\
(3)\end{array}$ & Fastbiol \\
\hline \multicolumn{6}{|l|}{ PARÁMETROS } \\
\hline $\mathrm{pH}$ & 7.89 & 8.2 & 6.8 & 6.8 & 3.75 \\
\hline $\mathrm{CE}\left(\mathrm{dS} \mathrm{m}^{-1}\right)$ & 19.28 & 15.3 & 11.2 & 10.2 & 25.70 \\
\hline Sólidos en suspensión ( $\mathrm{g} \mathrm{L}^{-1}$ ) & 19.52 & 23.6 & 8.85 & 9.78 & ---- \\
\hline Sólidos totales $\left(\mathrm{g} \mathrm{L}^{-1}\right)$ & ---- & ---- & --- & --- & 232.98 \\
\hline M.O. en solución $\left(\mathrm{g} \mathrm{L}^{-1}\right)$ & 5.28 & 5.4 & 2.86 & 3.75 & 181.10 \\
\hline \multicolumn{6}{|l|}{ MACRONUTRIMENTOS } \\
\hline $\mathrm{N}$ total $\left(\mathrm{mg} \mathrm{L}^{-1}\right)$ & 1876 & 980 & 1064 & 1015 & 4200 \\
\hline$P$ total $\left(\mathrm{mg} \mathrm{L}^{-1}\right)$ & 71.20 & 121 & 53.3 & 66.5 & 744.20 \\
\hline $\mathrm{K}$ total $\left(\mathrm{mg} \mathrm{L}^{-1}\right)$ & 1940 & 6760 & 1143 & 1045 & 17200 \\
\hline Ca total $\left(\mathrm{mg} \mathrm{L}^{-1}\right)$ & 104.80 & 220.4 & 755 & 707 & 5200 \\
\hline $\operatorname{Mg}$ total (mg L-1) & 27.60 & 53.4 & 348 & 353 & 1740 \\
\hline Na total $\left(\mathrm{mg} \mathrm{L}^{-1}\right)$ & 3400 & 542 & 463 & 500 & 1040 \\
\hline \multicolumn{6}{|l|}{ MICRONUTRIMENTOS } \\
\hline Fe Total $\left(\mathrm{mg} \mathrm{L}^{-1}\right)$ & 0.16 & --- & 5 & 12.5 & 516 \\
\hline Cu Total (mg L-1) & 2.28 & ---- & 0.3 & 0.4 & 14 \\
\hline Zn Total (mg L-1) & 1.36 & ---- & 1.9 & 2.9 & 60 \\
\hline Mn Total(mg L-1) & 14.08 & ---- & 1.8 & 2.7 & 28 \\
\hline B Total $\left(\mathrm{mg} \mathrm{L}^{-1}\right)$ & 5.20 & ---- & 124 & 93 & 19 \\
\hline
\end{tabular}

Fuente: (1) Biol Ventanilla Ciudad Saludable. Biol de origen porcino

(2) Biol Casablanca citado por Siura \& Davila, 2008.

(3) LASPAF 2001.

Análisis de interés agronómico del Fastbiol 20: El Fastbiol 20 contiene una alta concentración de $\mathrm{N}$ (Tabla 4), esto se debe a que el nitrógeno contenido en la materia prima (excretas de las vacas en producción) no se ha perdido como amoniaco debido al pH bajo (3.75) según el valor arrojado por los laboratorios de LASPAF y en condiciones de laboratorio fue de $\mathrm{pH}$ 4.02, este valor se mantuvo bajo por un período de 30 días que duró el experimento, por acción del ácido láctico, condición por el cual se evita que el nitrógeno se pierda rápidamente. Según Guerrero (1993) indica que los estiércoles y el guano tienen $\mathrm{pH}$ alcalino y por ello pierden rápidamente el $\mathrm{N}$, generando un fuerte olor amoniacal.

Estabilidad del Fastbiol 20: La estabilidad del Fastbiol 20 fue evaluado en base al control del pH, así como de la observación de los cambios físicos producidos por formación de gases, esto por hinchamiento del recipiente que lo contenía; olores y aspecto del producto en comparación con los demás tratamientos seleccionados que presentaron deformaciones en los recipientes, formaciones de capa superficial a manera de cubierta de coloración blanquecina y marrón, olores fuertes desagradables y de formaciones de burbujas. No obstante, la CE incrementó en el sistema, generado por la adición de melaza y B-lac en cada tratamiento.

Adicionalmente, a la variación de pH se calculó la relación $\mathrm{C} / \mathrm{N}$, dato que permite un mejor manejo agrícola de los abonos en cuanto a la estabilidad del producto, la relación C/N del Fastbiol 20 fue de 25, además, se realizó el cálculo $\mathrm{C} / \mathrm{N}$ del Fastbiol 20 antes del proceso de fermentación cuya composición fue de $65 \%$ excreta pre tratada, $20 \%$ melaza y $15 \%$ B-lac., mediante el cálculo de la proporción de las materias de mezcla dando como $\mathrm{C} / \mathrm{N}$ inicial de 18.11 (18:1)

En la Tabla 5, se observa la comparación de $\mathrm{C} / \mathrm{N}$ de un biol mediante biodigestión comparado con el Fastbiol 20.

Asimismo, la diferencia en el contenido de nitrógeno total entre ambos bioles se debe al proceso de degradación de materia orgánica distinto para la obtención de dichos abonos orgánicos líquidos. Fastbiol 20 presenta un mayor contenido de nitrógeno en forma nítrica (N$\left.\mathrm{NO}_{3}{ }^{-}\right)$y amoniacal $\left(\mathrm{N}-\mathrm{NH}_{4}{ }^{+}\right)$en comparación con el biol producido en forma artesanal, formas iónicas del nitrógeno de fácil absorción por las plantas.

El Fastbiol 20, se presentó estable en sus propiedades físicas y organolépticas durante los 30 días de evaluación, no presentó cambios físicos por deformación del recipiente en el que estuvo contenido, no presentó olores ni otra característica cualitativa de formación de capa superficial. Este resultado verifica que estuvo exento de agentes patógenos como se muestra en el análisis

Tabla 5. Comparación de propiedades químicas entre el Fastbiol 20 y un biol artesanal.

\begin{tabular}{lcc}
\hline PROPIEDADES QUÍMICAS & Biol $^{1}$ & Fast biol 20 \\
\hline Sólidos totales (\%) & 1.40 & 23.2 \\
Sólidos volátiles (\%) & 0.75 & $\mathrm{ND}$ \\
pH & $6.7-7.9$ & 3.75 \\
Carbono orgánico (\%) & $0.26-0.30$ & 10.50 \\
Relación C/N & $6.50-3.33$ & $25: 1$ \\
Nitrógeno total (\%) & $0.04-0.09$ & 0.42 \\
Nitrógeno amoniacal (ppm) & $200-400$ & 1400 \\
Nitrógeno nítrico (ppm) & 15 & 280 \\
Fósforo total ( $\left.\mathrm{P}_{2} \mathrm{O} 5\right)(\mathrm{ppm})$ & 400 & 744.20 \\
Fósforo disponible (ppm) & 48 & --- \\
Potasio total (K2)(ppm) & 1100 & 17200 \\
Potasio disponible (ppm) & 290 & ---- \\
Calcio soluble (\%) & 0.25 & --- \\
Ca Total (ppm) & ----- & 5200 \\
Magnesio soluble (\%) & 0.135 & \\
Mg total (ppm) & ----- & 1740 \\
Azufre (ppm) & 0.33 & -- \\
Zn (ppm) & 0.05 & 60 \\
Mn (ppm) & 0.005 & 28 \\
Cu (ppm) & 0.0017 & 14 \\
B (ppm) & 0.005 & 19 \\
\hline Fun &
\end{tabular}

Fuente: 1 Biol. Bioabono por Guerrero (1993). 
Tabla 6. Relación C/N del Fastbiol 20 y otros abonos orgánicos.

\begin{tabular}{lllr}
\hline Abono orgánico & \multirow{2}{*}{ Proceso bioquímico } & Abono & \multicolumn{2}{c}{ Relación } \\
& & C/N \\
\hline Comercial - líquido & Descomposición anaeróbica & Biol Casablanca & 3 \\
& & Biol con alfalfa & 1.56 \\
Líquido & Descomposición anaeróbica & Biol con chicha jora & 2.14 \\
Líquido & Fermentación & Fastbiol 20 (Consorcio ácido láctico B-lac) & 25 \\
\hline
\end{tabular}

microbiológico.

Por otra parte, la relación $\mathrm{C} / \mathrm{N}$ de bioles obtenidos por un proceso de biodigestión son menores comparados al Fastbiol 20, como se puede observar en el Tabla 6, esta diferencia es debido al proceso de fermentación homoláctica ocurrido en el Fastbiol 20, el carbono presente en el medio está bajo la forma de ácido láctico producido por el inoculante microbiano B-lac y no bajo las formas $\mathrm{CH}_{4}$ y $\mathrm{CO}_{2}$ que son liberados como productos de la biodigestión de las bacterias anaeróbicas. Asimismo, como resultado de la degradación biológica de la excreta pre tratada se obtuvo en el Fastbiol 20 mayor concentración del nitrógeno bajo las formas asimilables nítrica y amoniacal, dando como resultado un aumento de $\mathrm{C} / \mathrm{N}$ inicial de 18:1 a C/N del Fastbiol 20 de 25:1 resultado que muestra una mayor presencia de carbono bajo la forma de ácido láctico y disminución del nitrógeno total debido a que se encuentra bajo las formas nítrica $\left(\mathrm{N}-\mathrm{NO}_{3}{ }^{-}\right)$y amoniacal $\left(\mathrm{N}-\mathrm{NH}_{4}{ }^{+}\right)$.

\section{Conclusiones.}

Mediante el pre-tratamiento $80{ }^{\circ} \mathrm{C}$ por 15 min de las excretas frescas del ganado lechero y el tratamiento de fermentación anaerobia de las excretas pre tratadas, es posible obtener un abono orgánico líquido al quinto día de fermentación, Fastbiol 20 mediante el uso del Consorcio Microbiano B-lac a través de la técnica de fermentación homoláctica, que cumple la condición de mantener el pH cercano a 4.0 por un período de 30 días parámetro que permite que el abono sea estable.

Se comprobó que el pH inicial de las muestras de excretas frescas ejercen influencia en los valores de $\mathrm{pH}$ de los tratamientos; sin embargo, la tendencia del descenso rápido del $\mathrm{pH}$ al tercer día en ambas casos es notoria, así como la estabilidad lograda a partir del quinto día de iniciado el proceso de fermentación láctica.

El Fastbiol 20 tiene una concentración mayor de nitrógeno, fósforo y potasio, así como de micronutrimentos esto comparado con las concentraciones de dichos elementos en bioles comerciales. Además, el Fastbiol 20 según los análisis microbiológicos muestra ser un producto inocuo, libre de microorganismos patógenos que puedan generar riesgos en la salud a las personas en la manipulación de dicho abono, tampoco representa riesgo de contaminación en los suelos de cultivos por lo que es una propuesta alternativa para dar valor agregado al tratamiento de las excretas de los establos lecheros.

\section{Agradecimientos.}

Al Ing. Agr. Mg. Sc. Rubén Bazán Tapia por sus conocimientos compartidos sobre el cálculo de la relación $\mathrm{C} / \mathrm{N}$ y al Blgo. Mg. Sc. Julio Chia Wong por su apoyo en la corrección del abstract del presente artículo.

\section{Literatura citada.}

Aguilar F. \& Botero R. 2006. Los beneficios económicos totales de la producción de biogás utilizando un biodigestor de polietileno de bajo costo. Costa Rica. Tierra Tropical 2(1):15-25.

Aldon D. 2008. Estrategia Ambiental de aprovechamiento de la macroalga Ulva lactuca (lechuga de mar) a través del proceso de ensilaje. Tesis de Ingeniero Ambiental. Universidad Nacional Agraria La Molina. Lima-Perú.

AOAC (Association Official Analytical Chemists). 1998. Codex-Adapted 942.15.

Bossio F. 2007. Obtención de un biofertilizante basado en residuos de pescado y roca fosfatada. Tesis de Biólogo. Universidad Nacional Agraria La Molina. Lima - Perú.

Botero R. \& Preston, T. 1987. Biodigestor de bajo costo para la producción de combustible y fertilizante a partir de excretas. Manual para su instalación, operación y utilización. Centro para la Investigación en Sistemas Sostenibles de Producción Agropecuaria (CIPAV), Cali, Colombia. 30p.

Bourcourt R., Carrasco E., López A., Rodríguez Z. \& Gutiérrez, O. 2006. Microbiota aerobia en caña fermentada con excreta vacuna como alternativa alimentaria. Revista Cubana de Ciencia Agrícola, Tomo 40, No 3 pp. $279-281$.

Capman H. \& Pratt P. 1973. Métodos de análisis para suelos, plantas y aguas. Editorial Trillas. México. Uso de los laboratorios de LASPAF - Facultad de Agronomía- UNALM.

Garcés A., Berrio L., Ruiz S., Serna G. \& Builes A. 2004. Ensilaje como fuente de alimentación para el ganado. Revista Lasallista de Investigación, Vol. 1. Antioquia, Colombia. pp. 66-71.

García L. 2008. Uso de bacterias probióticas en el ensilado de residuos de pescado. Tesis de Biólogo. Universidad Nacional Agraria La Molina. Lima - Perú.

Gay S. \& Knowlton K. 2009. Ammonia Emissions and Animal Agriculture. Virginia Cooperative Extension. Virginia State, USA. pp 1-5

Guerrero J. 1993. Abonos orgánicos. Tecnologías para el manejo ecológico de suelos. RAAA. Lima-Perú. pp. 923; 81-83.

Herrero M. \& Gil S. 2008. Consideraciones ambientales de la intensificación en producción animal. Asociación Argentina de Ecología. Ecología Austral 18:273-289.

INIA (Instituto Nacional de Investigación Agraria). 2008. Folleto Producción y uso del biol. Serie $N^{\circ} 2$. 1era Edición. 
Koelsch R. \& Lesoing G. 1999. Nutrient balance on Nebraska livestock confinement systems. Journal of Animal Science. 77:63-71.

Labrador J. 2001. La materia orgánica en los agrosistemas. 1era Edición. Ediciones Mundi-Presa. España.

Madigan M., Martinko J. y Parker J. 2004. Biología de los microorganismos. Décima Edición. Pearson Educación, S. A. Madrid.pp 398-401.

Martínez A., Mendoza G., González S., Gómez A., Estrada M., De la Cruz E., Cruz A., Brito N. \& Pinos J. 2008. Evaluación in vitro de un ensilado de estiércol, rastrojo de maíz y melaza. Universidad Juárez Autónoma de Tabasco. México. Vol. 24, No 3 pp. 247-250.

Miller D., Berry E., Wells J., Ferrel C., Aschibeque S. \& Freetly H. 2006. Influence of genotype and diet on steer performance; manure odor, and carriage of pathogenic and other fecal bacteria. III. Odorous compound production. Journal Animal Science 84:2533-2545.

Peña N. 2008. Utilización de residuos de pota (Dosidicus gigas) para la elaboración de un fertilizante orgánico. Tesis de Ingeniero Ambiental. Universidad Nacional Agraria La Molina. Lima - Perú.
Prescott L., Harley J. \& Klein D. 2004. Microbiología. Quinta Edición. McGraw. Cap. 5, 6 y 23.

Rivas B., Segovia A., Morales H., Hermosillo J. \& Magaña, J. 2008. Plan de gestión para el desarrollo sostenible de explotaciones lecheras de la cuenca de Delicias. Tecnociencia Chihuahua. México. Vol. 2. No 1 pp. 4156.

Siura S. \& Davila S. 2008. Effect of green manure rotation, biol and cultivar on the production of organic spinach (Spinacea olearacea). 16th IFOAM. Organic World Congress. Modena. Italy. 4p.

Sotil F. 2007. Dinámica poblacional de los microorganismos del grupo de coliforme, en el proceso de biodegradación aeróbica y anaeróbica de los abonos líquidos orgánicos biol y purin. Tesis de Ingeniero Ambiental. Universidad Nacional Agraria La Molina. Lima-Perú.

Van Horn H., Wilkie A., Powers W. \& Nordstedt R. 1994. Components of Dairy Manure Management Systems. 1994. Journal Dairy Sciencie 77:2008-2030.

Vásquez S., Suárez H. y Zapata S. 2009. Utilización de sustancias antimicrobianas producidas por bacterias acido lácticas en la conservación de la carne. Rev. Chi. Nutr. Vol. 36, N¹. pp 64-71.

1 Colegio Mayor Secundario Presidente del Perú-Carretera Central Km. 24-Chaclacayo. Lima 08, Perú. lilianaperaltaveran@gmail.com; rosario.peralta@colegiomayor.edu.pe

2 Laboratorio de Biorremediación. Facultad de Ciencias, Universidad Nacional Agraria La Molina. Av. La Molina s/n, Lima 12, Perú. jjm@lamolina.edu.pe; jjmorales_2005@yahoo.es

${ }^{3}$ Departamento de Biología, Facultad de Ciencias, Universidad Nacional Agraria La Molina. Av. La Molina s/n, Lima 12, Perú. vmeza@lamolina.edu.pe 